\title{
Extreme traveler
}

\section{Krzysztof Korzeniewski ${ }^{1,2}$ (D)}

\author{
${ }^{1}$ Department of Epidemiology and Tropical Medicine; Military Institute of Medicine, Warsaw, Poland \\ ${ }^{2}$ Department of Occupational, Metabolic and Internal Diseases, Institute of Maritime and Tropical Medicine, \\ Medical University of Gdansk, Poland
}

\begin{abstract}
Although they may pose a serious health risk or may even turn out to be life-threatening, extreme sports, i.e. high-risk physical activities of varied difficulty, are growing in popularity among international travelers in recent years. Extreme sports encompass a wide range of activities such as scuba diving, rafting, surfing, bungee jumping and mountaineering. It is not unusual for travelers to engage in extreme sports far off the beaten path, in destinations where environmental conditions are difficult and specialist healthcare is not easily available. Therefore, before taking the decision to engage in any form of adventurous activity, travelers should be encouraged to take certain precautionary measures. The most important are: identification of potential health risk factors related to travel or the activity itself, physical conditioning and fitness training prior to travel (depending on the type of activity) and prophylaxis (a travel health kit, mandatory and recommended vaccinations, a pre-travel consultation to assess a person's fitness to travel and identify any potential contraindications for certain types of adventure sports, a comprehensive travel insurance policy). The article focuses on popular extreme sports, common risk factors associated with extreme activities as well as the recommended prophylaxis and precautionary measures.
\end{abstract}

(Int Marit Health 2020; 71, 4: 281-290)

Key words: travelers, extreme sports, health hazards, prevention

\section{INTRODUCTION}

Along with the increasing number of international tourist arrivals, the number of travelers who are interested in adventurous activities is also increasing. According to surveys as much as $40 \%$ of travelers reported that they have engaged in extreme sports, such as scuba diving, rafting, surfing, bungee jumping or mountaineering during their travel $[1,2]$. Extreme travel may be defined as participating in high-risk activities of varying degree of difficulty, usually in a remote destination where the environmental conditions are difficult and specialist healthcare is not readily accessible. The most popular destinations are both in developing countries located in tropical or sub-tropical zone, as well as in the wilderness of developed regions in temperate climate. Extreme sports encompass a wide range of activities that can be divided into several different categories. The most popular water sports include scuba diving, surfing, windsurfing and white-water rafting. As for the mountain sports, the most popular are skiing, snowboarding and mountaineering, while sky diving and paragliding are the top aerial activities. Other extreme sports such as bungee jumping or spelunking have also been gaining in popularity among travelers in recent years. When travelling abroad or engaging in extreme activities, travelers may encounter a wide range of health issues, either injuries or illnesses, which are normally treated or managed by specialists in travel or sports medicine. Therefore, it is necessary for health care professionals providing pre-travel advice to extreme travelers to have the basic knowledge on currently available prophylactic measures as well as potential risk factors - both environmental and activity-related [3]. Although a vast majority of extreme travelers were found to be between 30 and 40 years old, extreme travel is also popular with older people. The two principle causes of mortality in travelers were found to be cardiovascular diseases (in the elderly) and injuries (in younger voyagers) [4]. It is well known that prolonged physi-

Prof. Krzysztof Korzeniewski, MD, PhD, Military Institute of Medicine, Head of the Department of Epidemiology and Tropical Medicine, Szaserów St. 128, 04-141 Warsaw, 17 Poland; Medical University of Gdansk, Institute of Maritime and Tropical Medicine, Department of Occupational, Metabolic and Internal Diseases, Powstania Styczniowego St. 9B, 81-519 Gdynia, Poland, e-mail: kkorzeniewski@wim.mil.pl; kkorzeniewski@gumed.edu.pl 
Table 1. Selected types of extreme sports, risks and preventive measures

\begin{tabular}{|c|c|c|}
\hline Extreme sport & Health risks & Preventive measures \\
\hline Scuba diving & $\begin{array}{l}\text { Decompression sickness, drowning, } \\
\text { injuries (fauna and flora) }\end{array}$ & $\begin{array}{l}\text { Decompression in a hyperbaric chamber or in water } \\
\text { (if a hyperbaric chamber is unavailable) }\end{array}$ \\
\hline Surfing & Drowning, injuries & Surfing with an experienced surfer/instructor \\
\hline Rafting & Drowning, injuries & Using the services of certified operators \\
\hline Bungee jumping & Injuries & Using the services of certified operators \\
\hline $\begin{array}{l}\text { Skiing, snowboarding, } \\
\text { back country skiing }\end{array}$ & Injuries, avalanches & $\begin{array}{l}\text { Personal protective equipment, avalanche transceiver } \\
\mathrm{CO}_{2} \text { scrubber }\end{array}$ \\
\hline Mountaineering & $\begin{array}{l}\text { Acute mountains sickness, injuries, } \\
\text { hypothermia, sunburns, frost bites }\end{array}$ & $\begin{array}{l}\text { Experienced guides, supervised expedition with medi- } \\
\text { cal support, avoiding rapid ascents, acclimatization }\end{array}$ \\
\hline Spelunking & Injuries, drowning, infectious diseases & $\begin{array}{l}\text { Experienced guides, avoiding the activity during rain, } \\
\text { avoiding animal guano (bats), rabies vaccination }\end{array}$ \\
\hline
\end{tabular}

cal activity and emotional stress associated with travel may unmask or exacerbate a cardiovascular disease; therefore, it is particularly important that older patients have a pre-travel consultation and undergo a comprehensive medical examination before travel [5]. Myocardial infarctions normally occur within the first two days of travel [6]. Patients over the age of 50 with increased cardiovascular risk (e.g. obesity, arterial hypertension, and hypercholesterolemia) should at least have the electrocardiogram test performed before they travel. They should also be encouraged to have a specialist pre-travel consultation with a diabetologist (diabetes), endocrinologist (thyroid disease) and a dentist (to treat any dental problems). Women are additionally recommended to have a gynecological consultation before travel. It is important that extreme travelers receive all mandatory and recommended vaccinations and pack a travel health kit containing all regularly taken medicines [7, 8]. Health care professionals offering pre-travel advice to extreme or adventurous travelers have an obligation to provide their patients with good medical advice on how to deal with any potential travel-related risk factors or medical conditions they may develop while travelling. The two principle health risk factors include long-term travel and journeying to remote destinations with harsh climate and poor sanitation. The highest single risk for extreme travelers is trauma. Most injuries which are reported in adventurous travelers result from the activity itself or travelling by local public transport. In the developing countries, most injuries seen in travelers result from traffic accidents [9]. The risk for a motor vehicle collision is 6-fold higher when travelers are driving themselves, with an additional 2.5-fold higher risk if they need to drive on the opposite side of the road than in their home country $[10,11]$. In order to reduce the risk of traffic accidents and accident-related injuries, travelers should avoid travelling at night and must never drive under the influence of alcohol or without their seatbelts fastened [9, 12].

\section{TYPES OF EXTREME SPORTS}

Traditional, adventure activities have always been popular during journeys, but extreme sports are also becoming increasingly popular with both domestic and international travelers. Extreme sports are high-risk activities of varying difficulty (Table 1), which often require the use of professional equipment. Adventurous activities are performed in hazardous environments (on land, in the air or in water) and are usually associated with a high degree of risk because they involve high speed (rafting, skiing) or are practiced in extreme environmental or weather conditions (scuba diving, mountaineering) $[13,14]$. The typical mistake made by extreme travelers is the lack of preparation. Unfortunately, it is quite common that extreme travelers fail to purchase a comprehensive insurance policy covering for extreme sports injuries or forget to take a travel health kit with a supply of regularly taken prescription medications. They hardly ever seek pre-travel advice, although a consultation with an experienced health care professional might be very useful in assessing the health status of a traveler and identifying potential contraindications for certain types of adventure activities.

\section{SCUBA DIVING}

A vast number of tour operators globally offer short diving excursion as well as longer diving holidays. In countries with a developed tourist industry (e.g. Thailand, Belize, Australia) it is necessary to hire a certified local instructor for anybody willing to go on a diving excursion; in the developing countries, however, the law may not be so strict. The two greatest risks for divers include drowning and decompression sickness. The Diver's Alert Network is an organization that offers substantial support in case of emergency. The organization can provide comprehensive diving insurance, their personnel can find the nearest functional hyperbaric chamber and assist with the hyperbaric treatment. Scuba 
diving far away from functional hyperbaric chambers requires alternative strategies for dealing with decompression sickness. One such strategy includes in-water recompression, i.e. re-descending until symptoms subside and then slowly re-ascending with doubling one's decompression time. This strategy, however, requires considerable experience, sufficient air supply, good weather conditions and time [15]. A complete medical assessment of fitness to dive is a prerequisite for anyone planning to go scuba diving. Travelers willing to have a diving holiday, especially those who are planning to go diving for the first time, must be given a thorough medical examination on the basis of which an experienced health care provider will be able to identify potential risk factors and contraindications to dive. During such an examination, a physician will need to evaluate the condition of the diver's respiratory and cardiovascular systems, their ears and paranasal sinuses as well as assess their mental health; it will also be necessary to collect information on the patient's past medical history. Exposure to cold water, high ambient pressure and an increased volume of respiratory gases causes physiological and systemic changes which may unmask or aggravate certain pre-existing conditions $[16,17]$. During a diving fitness health assessment, special attention should be given to patients with:

- respiratory illnesses - diving is contraindicated in patients with asthma, bronchitis or pneumonia, patients who are susceptible to spontaneous pneumothorax, status post a thoracic surgery, airway obstruction or emphysema which can be seen on the chest X-ray; the above-listed conditions change the respiratory mechanics, in response to rapid changes in intrapulmonary pressures, a barotrauma may occur;

- illnesses of the ear and paranasal sinuses - diving is contraindicated in patients with chronic otitis media or sinusitis, marked stenosis of the auditory canal, perforated tympanic membrane; the above-listed conditions will make it difficult or impossible to equalize pressure in the ear and in sinuses while diving; being under water with perforated eardrum may lead to irritation of the labyrinth and disorientation;

- illnesses which may disturb consciousness, e.g. epilepsy or poorly controlled diabetes are a contraindication to diving;

- psychiatric illnesses and disorders - diving is contraindicated in patients with a psychosis, anxiety or personality disorders, intellectual disability, alcohol addiction or substance abuse;

- cardiovascular illnesses - diving is contraindicated in patients with poor exercise tolerance, a positive cardiac stress test and certain heart diseases (Table 2); the stress associated with diving increases blood pressure and can cause tachycardia, which in patients with cer- tain cardiovascular diseases (e.g. arterial hypertension, coronary heart disease) may result in acute myocardial infarction and sudden death (12\% of diving-related deaths are associated with cardiac events).

Pregnancy is another absolute contraindication to diving. Pregnant women should be discouraged from any diving-related activity as it may result in developmental anomalies in the fetus (as a result of the effects of high partial pressure of oxygen). Women who have had a natural birth are not recommended to go scuba diving for at least 4 weeks after they have given birth; while women who have had a Cesarean section should not scuba dive for 8-12 weeks after delivery. Scuba diving is relatively contraindicated in people with class 3 obesity (body mass index $>40$ ); obesity does not only decrease general physical fitness but it may also increase the risk of a decompression sickness due to a high content of total nitrogen in the body (nitrogen is more soluble in fat than in other tissues) [17-19].

People diving regularly should undergo a physical examination at regular intervals. The World Recreational Scuba Training Council (www.wrstc.com) has introduced the physical examination guidelines for determining fitness or absolute contraindications to diving. The guidelines have also been approved by the Divers Alert Network (www. diveralertnetwork.org) and the Undersea and Hyperbaric Medicine Society (www.membership.uhms.org) [20]. A health care provider assessing a person's fitness to dive will need to consider age and sex-related risk factors as well as the diver's underlying conditions. Divers over the age of 50 should be informed of the fact that they have a lower level of fitness compared to younger people and that some underlying conditions and medications are considered relative or absolute contraindications to diving. Aging is associated with a number of natural changes in the body. As the total muscle mass declines, the person's general level of fitness is getting lower. Also, because their blood pressure increases, older people have a higher risk of developing a cardiovascular disease. Any person over the age of 50 who is willing to go diving should have their blood pressure controlled through regular exercise, limiting the amount of sodium in their diet and taking hypotension medications. They are also strongly recommended to have a pre-travel consultation with a cardiologist to assess the risk of myocardial ischemia. Aging is also associated with certain metabolic changes. A decrease in insulin secretion and progressing insulin resistance may lead to glucose intolerance and the development of senile diabetes. Older adults are more prone to asymptomatic hypoglycemia, which is considered a contraindication to diving. Due to a reduced production of thyroid hormones, the elderly will naturally have a higher sensitivity to environmental temperature, and will therefore be more susceptible to hypothermia or a heat 
Table 2. Absolute and relative contraindications to recreational scuba diving [19]

\begin{tabular}{|c|c|c|}
\hline System & Absolute contraindications & Relative contraindications \\
\hline Pulmonary & $\begin{array}{l}\text { Spontaneous pneumothorax } \\
\text { Cystic or cavitating lesions } \\
\text { Active asthma, exercise-, emotional-, or } \\
\text { cold-induced bronchospasm }\end{array}$ & $\begin{array}{l}\text { Asthma } \\
\text { Obstructive and restrictive diseases } \\
\text { Interstitial diseases } \\
\text { Intrathoracic surgery } \\
\text { Pulmonary exercise impairment }\end{array}$ \\
\hline Ear, nose, throat & $\begin{array}{l}\text { Current tympanic membrane perforation } \\
\text { Tympanostomy tubes }\end{array}$ & $\begin{array}{l}\text { Recurrent infections (e.g., otitis media, sinusitis) } \\
\text { Eustachian tube dysfunction }\end{array}$ \\
\hline Neurological & $\begin{array}{l}\text { History of seizures or epilepsy } \\
\text { Intracranial tumors } \\
\text { History of transient ischemic attack or stroke } \\
\text { Spinal cord injury with neurological deficits } \\
\text { Significant motor deficits }\end{array}$ & $\begin{array}{l}\text { Peripheral sensory nerve deficits } \\
\text { Previous head injury } \\
\text { Chronic illnesses (e.g., multiple sclerosis) } \\
\text { Migraine }\end{array}$ \\
\hline $\begin{array}{l}\text { Endocrine and } \\
\text { metabolic }\end{array}$ & $\begin{array}{l}\text { Recently diagnosed diabetes or recent change } \\
\text { in medication }\end{array}$ & $\begin{array}{l}\text { Diabetes } \\
\text { Hormonal excess or deficiency }\end{array}$ \\
\hline $\begin{array}{l}\text { Behavioral or } \\
\text { psychological }\end{array}$ & $\begin{array}{l}\text { Psychosis or taking antipsychotics } \\
\text { History of panic disorder } \\
\text { Claustrophobia or agoraphobia }\end{array}$ & History of substance abuse \\
\hline Cardiovascular & $\begin{array}{l}\text { Ischemic heart disease } \\
\text { Intracardiac shunts } \\
\text { Valvular stenosis } \\
\text { Congestive heart failure } \\
\text { Hypertrophic cardiomyopathy } \\
\text { Dysrhythmias requiring medication } \\
\text { History of immersion pulmonary edema }\end{array}$ & $\begin{array}{l}\text { Previous ischemic heart disease or myocardial } \\
\text { infarction } \\
\text { Hypertension and antihypertensive medication } \\
\text { Valvular regurgitation } \\
\text { Cardiovascular exercise impairment }\end{array}$ \\
\hline Gastrointestinal & $\begin{array}{l}\text { Chronic or recurrent bowel obstruction } \\
\text { Abdominal wall hernias } \\
\text { Containing bowel } \\
\text { Severe reflux disease }\end{array}$ & $\begin{array}{l}\text { Peptic ulceration } \\
\text { Inflammatory bowel disease }\end{array}$ \\
\hline Other & $\begin{array}{l}\text { Pregnancy } \\
\text { Significant impairment of the senses } \\
\text { (e.g., blindness) }\end{array}$ & $\begin{array}{l}\text { Young age } \\
\text { Previous decompression illness } \\
\text { Low physical fitness } \\
\text { Third degree obesity }(\mathrm{BMI}>40)\end{array}$ \\
\hline
\end{tabular}

$\mathrm{BMI}$ - body mass index

stroke. Older adults are also more vulnerable to dehydration and suffer degenerative changes in the musculoskeletal system, which limit their physical fitness and mobility. Because of the above mentioned age-related changes in the body, increased prevalence of underlying conditions and long-term pharmacotherapy or polypharmacy (defined as taking multiple medications daily, frequently associated with increased risk of adverse drug events or drug-drug interactions), the older travelers are strongly encouraged to have a consultation with a specialist and have all the necessary tests performed prior to making a decision to go scuba diving [17].

Although there are no formal age restrictions, the minimum age for recreational diving is considered to be 12 years, on condition that the child is physically and mentally fit for diving (they have enough physical strength to carry scuba equipment and are emotionally mature) and has no contraindications to diving. Under the Polish law, diving and diving lessons are allowed in children over the age of
10 years old; but younger children have been reported to go scuba diving under the supervision of an expert instructor. However, most experts will agree that children should not be allowed to dive with their own scuba set using gas mixtures or compressed air because they have a significantly higher risk of pulmonary barotraumas compared to adults (according to most diving medicine specialists young children and adolescents $<16$ years old should only be allowed snorkeling). Those who support children's diving assume that diving at a shallow depth is relatively safe. They are either unaware of the fact or they have forgotten that when a diver is breathing compressed air there is no such thing as a 'safe depth' because pulmonary barotraumas can occur even when a diver is ascending rapidly from the depth as low as $120 \mathrm{~cm}$. Also, children are more at risk from ear barotraumas than most adults. This is because children are predisposed to middle ear infections, which in turn can lead to Eustachian tube dysfunction. Additionally, children under the age of 12 will generally find it more difficult to 
perform the Valsalva maneuver in order to equalize pressure in the middle ear (the Eustachian tube in children is shorter and at a more horizontal angle). Another important issue to consider is the fact that diving may affect bone development (micro bubbles entering the circulatory system may damage the epiphyseal plate of the long bones and inhibit their growth). To minimize the risk of a decompression sickness, children should not be allowed to descend deeper than 9 meters [17].

With respect to women divers, the only absolute contraindication to diving is during pregnancy. Women who experience severe headaches or heavy bleeding during menstruation, which could affect their physical fitness, should be temporarily discouraged from diving [16]. Some researchers claim that oral contraceptives increase the risk of a decompression sickness, which might be associated with changes in blood coagulation. It has been estimated that women have a higher risk of developing a decompression sickness because in general they have more body fat than men (an average of $25 \%$ in females vs. $14 \%$ in males) [17].

A large number of recreational divers need to take medications (e.g. to treat their underlying conditions or as chemoprophylaxis). Most drugs are not contraindicated in divers; there are some medications, however, which are absolutely or relatively contraindicated in divers. People who have just started a new drug regimen should report any side effects or adverse events that have occurred to their health care provider so that the medication can be changed before they go diving [21-23]. Table 3 shows the information on selected medications and their possible side effects or adverse events in divers.

According to the Divers Alert Network, cardiovascular diseases are the second most common cause of death in divers. Therefore, pre-travel assessment of fitness to dive is particularly important for patients with cardiovascular conditions [24]. Mild-to-moderate asthma with normal spirometry should not be considered an absolute contraindication to diving [25]. Diabetic patients can be considered fit to dive on condition that they receive a fixed-dose insulin therapy for at least 12 months or oral antidiabetic agents for at least 3 months before a dive; their level of $\mathrm{HbA} 1 \mathrm{c}$ is $\leq 9.0 \%$; they had no episodes of hyperglycemia or hypoglycemia within 12 months before diving [26]. Diving-related morbidity is not much different from morbidity rates associated with other sports. The incidence of decompression sickness has been estimated at 5-80 cases per 100,000 dives [27]. According to the American and European Divers Alert Network reports, the incidence of diving-related deaths has been estimated at $1 / 6000$ dives per year. By contrast, the risk of jogging-related death is $1 / 7700$ joggers per year [28]. Officially, drowning has been reported the major cause of diving associated
Table 3. Selected medications and their possible adverse effects in divers [18]

\begin{tabular}{|c|c|}
\hline Medications & Note \\
\hline Narcotic/analgesic & $\begin{array}{l}\text { Narcotic - contraindicated; NSAIDs - no } \\
\text { contraindications }\end{array}$ \\
\hline Cardiac & $\begin{array}{l}\text { Some hypotension medications can reduce } \\
\text { exercise tolerance }\end{array}$ \\
\hline Insulin & $\begin{array}{l}\text { Blood glucose concentration should be } \\
\text { checked before each dive }\end{array}$ \\
\hline Antidepressant & Contraindicated \\
\hline Anticonvulsant & Contraindicated \\
\hline Antimalarial & $\begin{array}{l}\text { Mefloquine - contraindicated; doxycycline, } \\
\text { atovaquone/proguanil - no contraindica- } \\
\text { tions }\end{array}$ \\
\hline Sympathomimetics & $\begin{array}{l}\text { Pseudoephedrine can reduce the risk of } \\
\text { pressure-related ear injury }\end{array}$ \\
\hline $\begin{array}{l}\text { Anti-motion } \\
\text { sickness }\end{array}$ & $\begin{array}{l}\text { Cause sedation, impair the activity } \\
\text { of central nervous system }\end{array}$ \\
\hline
\end{tabular}

fatalities. In practice, however, the major areas of concern for specialists in diving medicine are issues associated with the use of breathing mixtures or hasty ascents as well as management of divers with underlying conditions which are contraindications to scuba diving $[24,28]$.

\section{SURFING}

Surfing is a type of activity which requires a good level of physical fitness. Surfing-related injuries are quite common, especially in beginner surfers. In expert surfers they occur at a rate of 2.7-4.0 per 1000 surfing days. Most of the injuries occur while riding waves (higher waves are typically associated with a greater risk of an injury) but also while surfing over a coral reef rather than a sandy bottom [29]. It is less common for a surfer to sustain an injury while lying on the surfboard and paddling it, diving under or through a wave or getting into or out of water. Surfing-related injuries usually result from a collision with a surfboard, particularly its fins [30]. Injuries from sea creatures, like jellyfish, sea urchins and stingrays, are rare among surfers [31]. Most surfing-associated injuries affect the head, face, eyes, ears, extremities and trunk. The most common types of injuries are contused or lacerated wounds to the head, face or extremities (being the result of a collision with the seabed or the surfboard or contact with a coral reef, rocks or sea urchins) as well as fractures of the lower extremities, the skull, the face or cervical spine [29]. Head traumas resulting from a collision with the sea floor or the surfboard, can cause concussion, loss of consciousness and eventually drowning [31]. While an eye injury which has been a result of hitting the surfboard or its fins can cause eyeball rupture or orbital 
fracture. The common extremity injuries include lacerations, sprains or fractures. Chest injuries with rib fractures usually result from a collision with a surfboard and spinal injuries are typically caused by hitting the seabed [32]. The back pain resulting from isometric hyperextension of the spine during paddling is the most common health problem among surfers [29]. Surfers not wearing neoprene wetsuits are recommended to use cream or lotion to protect their skin from sunburns and the effects of the wind and cold as well as wax their surfboard with special surfboard wax [29]. Swimming is the fundamental ability that every surfer should have; before learning to surf in water they should first have conditional and fitness training out of water. In order to avoid injuries surfers should be encouraged to wear wetsuits (which protect them from hypothermia, sunburn and skin abrasions), ear plugs (to protect their ears) and puncture-proof footwear which will reduce the risk of foot injuries. Rubber nose and fin guards will reduce the severity of injuries in case of a collision with the surfboard [29, 31]. The risk of an accident or an injury can be minimized by following the recommended surf safety rules (surfing with another person; avoiding areas packed with other surfers; being aware of the currents, local flora and fauna; knowing the depth of the sea or the ocean; paying attention to warning signs) [29].

\section{RAFTING}

White water rafting is a type of extreme activity of riding in a raft along a river with a strong current and rapids. The risks associated with white-water rafting can be classified into several different categories: injuries sustained from a collision with another person or hitting something inside or outside the raft; risks associated with freshwater exposure; overexertion and musculoskeletal overload associated with paddling; risks related with post-traumatic stress [33, 34]. Most injuries occur when a rafter is hit with a paddle or falls out of the raft, in such cases there is a high risk of drowning or sustaining a serious injury from smashing against the rocks $[33,35]$. The injuries which are most commonly reported among rafters include: contused or lacerated wounds, sprains, fractures and contusions; mostly in the head or face (eyes, lips, nose, teeth) and knees [34, 36]. Injuries to the face are more common in women, while injuries to extremities are more frequent in men. Because on average women are physically weaker than men, they tend to sit in the middle or at the back of the raft. If the raft capsizes rafters who are sitting in the front section (usually men) collide with the people at the back, which can cause injuries in both [36]. The incidence of rafting-related injuries has been estimated at 26-44 per 100,000 people [34, 35]. Lack of adequate training (a typical training session before a rafting tour takes no more than $30 \mathrm{~min}$ ) and poor fitness of the participants pose additional risks for white water rafters, especially if rafting takes place in more dangerous settings and in rivers with very strong currents and rapids. Exposure to contaminated freshwater carries additional risk for rafters. There have been reports of outbreaks of infectious diseases among rafters, such as an outbreak of leptospirosis (in Costa Rica) [37], schistosomiasis (within the tributaries of the Nile in Uganda) [38] and of giardiasis [34]. If there is increased risk of exposure to contaminated fresh water and of developing leptospirosis during white water rafting, doxycycline in a single dose of $200 \mathrm{mg}$ taken weekly is recommended as prophylaxis [37]. White water rafting operators have an obligation to provide each participant with personal protective equipment such as a helmet and a life jacket, while rafters are strongly recommended to do conditioning training before they go white water rafting [35].

\section{BUNGEE JUMPING}

There is little data available on bungee jumping related injuries. The only exception being the well documented cases of fatal accidents, mostly caused by the cord or harness failure, in which people fell to the ground and died because the landing spot had not been secured with a safety air cushion. The most common traumas include eye injuries associated with free falling and a rapid change of speed, in particular retinal, subconjunctival or vitreous hemorrhage. The lesions can be either unilateral or bilateral and may lead to vision impairment or seeing floaters [39]. Other, less common injuries include: traumatic carotid artery dissection, pulmonary hemorrhage, subdural hemorrhage, a dislocated shoulder, peroneal nerve palsy [13, 40]. Prevention of injuries is primarily based on a medical examination and assessing a person's fitness to bungee jump. Patients with vascular or ocular conditions are considered to have a higher risk of a bungee jumping related injury [13].

\section{SKIING, SNOWBOARDING}

Both skiing and snowboarding are considered quite dangerous and can result in a wide range of sports injuries (affecting the head, lower and upper limbs, bones, joints). With regard to snowboarders, who represent approximately $30 \%$ of winter sports fans, injuries were found to be most common in beginners. Most skiing- and snowboarding-related injuries are reported in men because they tend to ski faster and in a more risky manner compared to women [13]. In general, injury rates have been shown to be higher among beginner skiers and snowboarders because of their lack of skill and experience. Most skiing or snowboarding related injuries occur from falls on the slope or as a result of a collision with other skiers or snowboarders (the risk is 3-fold higher for skiers compared to snowboarders) [41, 42]. Skiers are much more likely to suffer sprains or injuries 
of the lower limbs, in particular anterior cruciate ligament injuries, compared to snowboarders. On the other hand, wrist and spine injuries are more common in snowboarders. Some authors have suggested that snowboarders have higher rates of head trauma and concussion as well as bone fractures in particular ankle fractures [43] in comparison to skiers [44]. Prevention of accidents and injuries is not only the matter of good technical training and physical preparation, but also of high-quality safety gear. A good helmet can prevent a head injury while wrist guards are particularly useful for snowboarders [42]. Backcountry snow skiing is yet another type of extreme activity, which needs to be given special consideration. An important risk associated with backcountry skiing is the risk of avalanches, which is particularly high during the winter months and that can never be fully eliminated, even if a traveler has all the necessary experience and is well prepared. Approximately $90 \%$ of avalanches occur on slopes of between $30^{\circ}$ and $45^{\circ}$, usually after a heavy snowfall, i.e. when the conditions for skiing seem to be perfect. Skiers are recommended to travel in groups and to have equipment which in case of emergency may save their life (an avalanche transceiver, a shovel, a $\mathrm{CO}_{2}$ scrubber) [45]. A study carried out by Radwin et al. [46] demonstrated that in most avalanche victims $\mathrm{CO}_{2}$ necrosis occurs much faster than hypoxia or hypothermia, which means that $\mathrm{CO}_{2}$ scrubbers offer the best chance of survival for avalanche victims.

\section{MOUNTAINEERING}

Mountaineering at altitudes higher than 2500 meters above sea level or quick ascent are associated with a number of health risk factors, which include climbing-related injuries, hypoxia-induced illnesses and conditions which are attributable to the effects of cold or the sun [47]. The most common climbing-related illnesses are those associated with exposure to hypobaric and hypoxic conditions. The progression rate of the illness and the severity of symptoms will primarily depend on the elevation (at higher altitudes the atmospheric pressure decreases, and so does the oxygen content), time of exposure (hours, days, weeks), and the rate of ascent. The major risk factors for developing a high-altitude illness are associated with acclimatization, intensity of exercise, physical and mental condition of a climber and pre-existing illnesses. Acute mountain sickness (AMS) is the most common of the altitude-related illnesses in mountain climbers who have quickly changed elevation. A total of $10-20 \%$ of people who have climbed $1800-2400$ meters in less than 24 hours develop the symptoms of AMS. A majority of climbers who have climbed 3400-4300 meters suffer mild symptoms of AMS, while $12-18 \%$ may develop a severe form of AMS. The condition normally presents with headaches, dizziness, nausea and vomiting, loss of appetite, sleep disorders and shortness of breath. The symptoms of AMS may affect those who have climbed from low to high altitude (e.g. from $500 \mathrm{~m}$ to $3000 \mathrm{~m}$ above sea level) within a short period of time, as well as those who, being at a high altitude, have climbed even higher. Thus, the cause of AMS is not high altitude itself, but rather making a quick ascent within a short period of time [47]. A total of $25-35 \%$ of passengers who have had a direct flight from lowland to highland destinations e.g. Lhasa in Tibet $(3650 \mathrm{~m}$ above sea level) or La Paz in Bolivia (3800 m above sea level) develop symptoms of AMS [48]. AMS is best prevented by gradual acclimatization and discontinuation of further ascent if symptoms occur. The condition can be treated by descending to a lower altitude, administration of drugs and oxygen therapy (a portable hyperbaric chamber e.g. Gamow bag may be effective if it is available) [49]. According to study findings, acetazolamide has been most effective for prophylaxis and treatment of AMS; the drug accelerates acclimatization through its diuretic effect, improves ventilation and sleep breathing patters. Acetazolamide does not mask the symptoms of AMS and can also be used for therapeutic purposes. The prophylactic dose in adults is $125-250 \mathrm{mg}$ taken every 12 hours at least 24 hours before ascent, the therapy should continue for at least 48 hours after arrival at the highest altitude. Treatment doses of the drug are $250 \mathrm{mg}$ taken every 12 hours; they should be continued for 24 hours after symptoms have subsided or after descent to a safer altitude [48]. High altitude pulmonary edema (HAPE) and high altitude cerebral edema (HACE) are the other two common conditions which are associated with hypobaric and hypoxic conditions. Unlike acute mountain sickness, HAPE and HACE may be life-threatening. The conditions are caused by decreased partial pressure of oxygen which leads to functional disorders, primarily of the central nervous system as well as the circulatory and respiratory systems. The progression rate of the illness and the severity of symptoms will mostly depend on the elevation itself, but also on a number of other factors such as age, physical and mental condition of a climber, hydration level, the use of medications as well as time of exposure to high altitude conditions and the rate of ascent [49]. HAPE is usually associated with hypoxia (resulting from pulmonary hypertension) and pulmonary edema (being the effect of increased vascular permeability). The estimated incidence of HAPE may range from $0.01 \%$ to even $15 \%$ in those rapidly climbing to very high altitudes and covering the distance of more than $\mathbf{2 4 0 0}$ meters within a short period of time; other risk factors that increase the incidence of HAPE include genetic predisposition and past history of the condition [48]. Unlike AMS or HAPE, the incidence of HACE in climbers is much lower and is usually reported in climbers who have ascended to more than 3600 meters. In general, prolonged 
exposure to hypoxic conditions increases permeability of cerebral vessels, thus, leading to edema. Other common medical problems that are reported in climbers include peripheral edema (usually affecting the lower or upper limbs or the face), retinal hemorrhage (usually asymptomatic), thromboembolism, immunosuppression and slow healing of wounds. Climbers are also at a higher risk of developing conditions associated with the exposure to cold (hypothermia, frost bites, chilblains, trench foot, respiratory illnesses) or intense sunlight (sunburns, snow blindness) [47]. All climbers are strongly recommended to have a pre-travel consultation before they go mountaineering. A pre-travel consultation is a good opportunity to assess a person's fitness to climb and identify any potential underlying conditions, this is extremely important because exposure to extreme environmental conditions may unmask or aggravate certain diseases. Climbers are also recommended to have a dentist appointment because exposure to hypoxic and hypobaric conditions can exacerbate inflammatory lesions of the pulp or periodontium. While travelers with pre-existing respiratory or cardiovascular diseases are encouraged to have a pre-travel consultation with their specialist. Severe chronic obstructive pulmonary disease, pulmonary hypertension presenting with clinical signs, decompensated heart failure and sickle-cell anemia are absolute contraindications to mountaineering [49].

\section{SPELUNKING}

Remote and technically difficult cave exploration has been increasing in popularity among travelers in recent years. In principal, the major health risks include trauma and drowning in a flash flood, e.g. during a rainy season. In developing countries, quick evacuation may not be an option as the medical capabilities are limited. For their own safety, cave explorers are advised to inform local authorities of their plans, and organize the medical and evacuation support on their own. Spelunking is also associated with certain infectious risks, with histoplasmosis, a fungal infection caused Histoplasma capsulatum, being the most common cave-associated illness. The disease is transmitted through exposure to bird or bat guano, which is contaminated with infective spores [50,51]. The biggest risk for spelunkers, however, is from rabies, a disease which is fatal for humans. Cave-associated rabies is primarily transmitted from infected bats (bats account for $17 \%$ of all rabies cases in animals in the USA) [52]. Spelunkers need to be aware of the fact that rabies is not only transmitted through direct contact with an infected bat, but it can also spread indirectly, i.e. through exposure to the animal's saliva, or even through aerosol transmission. This is possible with very large colonies of bats living in poorly ventilated caves with high humidity and temperature [53]. Rabies can be best prevented through pre-exposure vaccination; in line with the proposed guidelines the rabies vaccine is "administered in 3 doses on days 0, 7 and 21 or 28; a complementary dose is administered 12 months after the primary course; booster doses are recommended every 5 years). In case of a direct contact with potentially rabid bats (being bitted or scratched), their feces or other secretions, it will be necessary to receive post-exposure vaccination. In patients who have received pre-exposure vaccination (in the last 5 years) post-exposure vaccination consists of 2 doses: the first on the day of exposure and the second 3 days after. In travelers who have not been immunized (their last vaccination was more than 5 years before, they have not completed the full vaccination course or have never received pre-exposure vaccination) post-exposure vaccination requires the administration of 5 doses of the rabies vaccine on days: 0 (the day of exposure), $3,7,14$ and 28. Before administering the first dose of the vaccine, a non-immunized individual should also receive immunoglobulin RIG (HRIG: 20 IU/kg body mass or ERIG: $40 \mathrm{IU} / \mathrm{kg}$ body mass)" [12]. Another risk associated with spelunking is the risk of exposure to water contaminated with rodent or bat droppings or urine. Cave water tends to have a higher $\mathrm{pH}$, which facilitates the growth of Leptospira, and may therefore be a potential source of leptospirosis. The best preventive measure against the disease is the administration of a single $200 \mathrm{mg}$ dose of doxycycline weekly [54].

\section{TRAVEL INSURANCE POLICY}

If travelers are going to engage in any form of extreme activities, they are strongly recommended to purchase a comprehensive travel insurance policy that would cover for the cost of treatment and assistance. The choice is normally between the basic and extended insurance coverage, but extreme travelers need to be aware of the fact that most extreme activities are normally excluded from basic insurance plans. The typical travel insurance exclusions are [15]:

- scuba diving;

- jet skiing;

- animal or motor vehicle racing;

- spelunking;

- hang gliding, sky diving, parachuting, bungee jumping;

- air sports, aviation (except as a passenger on a commercial flight);

- skiing and snowboarding, except for the purpose of recreation (no insurance coverage in case of backcountry skiing/snowboarding or skiing/snowboarding against the advice of the local ski instructors of local authorities);

- mountaineering with the use of professional equipment (ropes) or above 4500 meters above sea level;

- any other sporting activity associated with an increased risk of injury. 
Extreme travelers are recommended to purchase a travel insurance policy covering for the costs of medical evacuation and repatriation and the costs of an emergency rescue operation which are not usually covered by the standard accident insurance policy. Their insurance policy should also cover for the costs of specialist treatment (e.g. treatment in a hyperbaric chamber for divers with decompression sickness), the costs of an emergency rescue operation at sea or in the mountains and include third party liability insurance (personal injury and property damage). The price of such comprehensive travel insurance will naturally depend on a variety of factors such as the nature of extreme sports (professionals vs. amateurs) or any underlying medical conditions an extreme traveler may have. Travelers need to bear in mind that their insurance company may refuse to pay the claim if damage or incident was associated with misuse of alcohol, drugs or other illegal substances [12].

\section{REFERENCES}

1. Gundacker ND, Rolfe RJ, Rodriguez JM. Infections associated with adventure travel: A systematic review. Travel Med Infect Dis. 2017; 16: 3-10, doi: 10.1016/j.tmaid.2017.03.010, indexed in Pubmed: 28351605.

2. Caine DJ. The epidemiology of injury in adventure and extreme sports. Med Sport Sci. 2012; 58: 1-16, doi: 10.1159/000338558, indexed in Pubmed: 22824836.

3. Goodyer L, Gibbs J. Medical supplies for travelers to developing countries. J Travel Med. 2004; 11(4): 208-211, doi: 10.2310/7060.2004.19003, indexed in Pubmed: 15541222.

4. Jong EC. Approach to Travel Medicine and Contents of a Personal Travel Medicine Kit. In: Sanford CA, Pottinger PS, Jong EC (Eds). The Travel and Tropical Medicine Manual. 5th Edition. Marickville, Elsevier 2017.

5. Christenfeld N, Glynn LM, Phillips DP, et al. Exposure to New York City as a risk factor for heart attack mortality. Psychosom Med. 1999; 61(6): 740-743, doi: 10.1097/00006842-199911000-00003, indexed in Pubmed: 10593623.

6. Kop WJ, Vingerhoets Ad, Kruithof GJ, et al. Risk factors for myocardial infarction during vacation travel. Psychosom Med. 2003; 65(3): 396-401, doi: 10.1097/01.psy.0000046077.21273.ec, indexed in Pubmed: 12764212.

7. Wilder-Smith A, Khairullah NS, Song JH, et al. Travel health knowledge, attitudes and practices among Australasian travelers. J Travel Med. 2004; 11(1): 9-15, doi: 10.2310/7060.2004.13600, indexed in Pubmed: 14769281.

8. Cabada MM, Maldonado F, Mozo K, et al. Pre-travel preparation for Cusco, Peru: a comparison between European and North American travelers. J Travel Med. 2010; 17(6): 382-386, doi: 10.1111/j. 1708-8305.2010.00461.x, indexed in Pubmed: 21050317.

9. Odero W, Garner P, Zwi A. Road traffic injuries in developing countries: a comprehensive review of epidemiological studies. Trop Med Int Health. 1997; 2(5): 445-460, indexed in Pubmed: 9217700.

10. Carey M, Aitken M. Motorbike Injuries in Bermuda: A Risk for Tourists. Annals of Emergency Medicine. 1996; 28(4): 424-429, doi: 10.1016/s0196-0644(96)70009-4.

11. Petridou E, Askitopoulou H, Vourvahakis D, et al. Epidemiology of road traffic accidents during pleasure travelling: the evidence from the island of Crete. Accid Anal Prev. 1997; 29(5): 687-693, doi: 10.1016/s0001-4575(97)00038-9.

12. Korzeniewski K. Medycyna podróży. Kompendium [in Polish]. Wydawnictwo Lekarskie PZWL, Warszawa 2016.

13. Gomez AT, Rao A. Adventure and Extreme Sports. Med Clin North Am. 2016; 100(2): 371-391, doi: 10.1016/j.mcna.2015.09.009, indexed in Pubmed: 26900120.

14. Young CC. Extreme sports: injuries and medical coverage. Curr Sports Med Rep. 2002; 1(5): 306-311, doi: 10.1249/00149619200210000-00009, indexed in Pubmed: 12831694.

15. Boulware DR. Travel medicine for the extreme traveler. Dis Mon. 2006; 52(8): 309-325, doi: 10.1016/j.disamonth.2006.08.004, indexed in Pubmed: 17101310.

16. Lynch JH, Bove AA. Diving medicine: a review of current evidence. J Am Board Fam Med. 2009; 22(4): 399-407, doi: 10.3122/jabfm.2009.04.080099, indexed in Pubmed: 19587254.

17. Krzyżak J, Korzeniewski K. Medycyna dla nurkujących [in Polish]. Wydawnictwo 4Font 2020, Poznań 2020.

18. Marienau KJ, Arguin PM. Diving Medicine. In: Keystone JS, Freedman DO, Kozarsky PE, Connor BA, Nothdurft HD. [Eds]. Travel Medicine. Third Edition. Saunders, Philadelphia, PA 2013: 373-378.

19. Meintjes J. Diving Medicine. In: Keystone JS, Kozarsky PE, Connor BA, Northdurft HD, Mendelson M, Leder K. Travel Medicine. Fourth Edition. Elsevier Inc., USA 2019: 401-406.

20. Medical guidelines. Recreational Scuba Training Council. http:// www.wrstc.com/downloads/10\%20-\%20Medical\%20Guidelines. pdf (Accessed: 28 Sept 2017).

21. Harrison D, Lloyd-Smith R, Khazei A, et al. Controversies in the medical clearance of recreational scuba divers: updates on asthma, diabetes mellitus, coronary artery disease, and patent foramen ovale. Curr Sports Med Rep. 2005; 4(5): 275-281, doi: 10.1097/01. csmr.0000306222.19714.33, indexed in Pubmed: 16144586.

22. Dowse MS, Cridge C, Smerdon G. The use of drugs by UK recreational divers: prescribed and over-the-counter medications. Diving Hyperb Med. 2011; 41(1): 16-21, indexed in Pubmed: 21560980.

23. Leigh D. DAN discusses malaria and antimalarial drugs. Alert Diver, September 2020. http://www.diversalertnetwork.org/medical/ articles/article.asp?articleid=80 (Accessed: 28 September 2017).

24. Denoble PJ, Caruso JL, Dear G. Common causes of open-circuit recreational diving fatalities. Undersea Hyperb Med. 2008: 393-406, doi: 19175195.

25. Godden D, Currie G, Denison D, et al. British Thoracic Society guidelines on respiratory aspects of fitness for diving. Thorax. 2003; 58(1): 3-13, doi: 10.1136/thorax.58.1.3, indexed in Pubmed: 12511710.

26. Pollock NW, Uguccioni DM, Dear Gde L. [Eds]. Diabetes and recreational diving: guidelines for the future. Proceedings of the UHMS/DAN 2005 June 19 Workshop. Durham, NC: Divers, Alert Network 2005. Guidelines available at. http://www.diversalertnetwork.org/news/ download/SummaryGuidelines.pdf (Accessed: 28 September 2017).

27. Bove AA, Moon RE. Patent foramen ovale - is it important to divers? In: Alert Diver, Sept/Oct 2004. http://diversalertnetwork.org/medical/ articles/article.asp? articleid=70 (Accessed: 28 September 2017).

28. Vann RD, Lang MA. [Eds]. Recreational Diving Fatalities. Proceedings of the Dives Alert Network 2010 April 8-10 Workshop. Durham, NC. Available at:. http://d35gjurzz1vdcl. cloudfront.net/ftw-files/Fatalities_Proceedings.pdf (Accessed: 28 September 2017).

29. Sunshine S. Surfing Injuries. Current Sports Medicine Reports. 2003; 2(3): 136-141, doi: 10.1249/00149619-200306000-00005, indexed in Pubmed: 12831652.

30. Nathanson A, Bird S, Dao L, et al. Competitive surfing injuries: a prospective study of surfing-related injuries among con- 
test surfers. Am J Sports Med. 2007; 35(1): 113-117, doi: 10.1177/0363546506293702, indexed in Pubmed: 17021312.

31. Nathanson A, Haynes P, Galanis D. Surfing injuries. Am J Emerg Med. 2002; 20(3): 155-160, doi: 10.1053/ajem.2002.32650, indexed in Pubmed: 11992332.

32. Sano A, Yotsumoto T. Chest injuries related to surfing. Asian Cardiovasc Thorac Ann. 2015; 23(7): 839-841, doi: 10.1177/0218492315591103, indexed in Pubmed: 26071603.

33. Fiore DC, Houston JD. Injuries in whitewater kayaking. Br J Sports Med. 2001; 35(4): 235-241, doi: 10.1136/bjsm.35.4.235, indexed in Pubmed: 11477016.

34. Fiore D. Injuries Associated With Whitewater Rafting and Kayaking. Wilderness \& Environmental Medicine. 2003; 14(4): 255-260, doi: 10.1580/1080-6032(2003)14[255:iawwra]2.0.co;2.

35. Wilson I, McDermott H, Munir F, et al. Injuries, ill-health and fatalities in white water rafting and white water paddling. Sports Med. 2013; 43(1): 65-75, doi: 10.1007/s40279-012-0007-8, indexed in Pubmed: 23315757.

36. Whisman SA, Hollenhorst SJ. Injuries in commercial whitewater rafting. Clin J Sport Med. 1999; 9(1): 18-23, doi: 10.1097/00042752199901000-00004, indexed in Pubmed: 10336047.

37. Centers for Disease Control and Prevention (CDC). Outbreak of leptospirosis among white-water rafters-Costa Rica, 1996. MMWR Morb Mortal Wkly Rep. 1997; 46(25): 577-579, indexed in Pubmed: 9214567.

38. Morgan OW, Brunette G, Kapella BK, et al. Schistosomiasis among recreational users of Upper Nile River, Uganda, 2007. Emerg Infect Dis. 2010; 16(5): 866-868, doi: 10.3201/eid1605.091740, indexed in Pubmed: 20409387.

39. Jain AK, Gaynon M. Images in clinical medicine. Macular hemorrhage from bungee jumping. N Engl J Med. 2007; 357(3): e3, doi: 10.1056/ NEJMicm064881, indexed in Pubmed: 17634454.

40. Manos D, Hamer O, Müller NL. Pulmonary hemorrhage resulting from bungee jumping. J Thorac Imaging. 2007; 22(4): 358-359, doi: 10.1097/RTI.0b013e31813fab8b, indexed in Pubmed: 18043394.

41. Wijdicks CA, Rosenbach BS, Flanagan TR, et al. Injuries in elite and recreational snowboarders. Br J Sports Med. 2014; 48(1): 11-17, doi: 10.1136/bjsports-2013-093019, indexed in Pubmed: 24282020.

42. Hume PA, Lorimer AV, Griffiths PC, et al. Recreational snow-sports injury risk factors and countermeasures: a meta-analysis review and Haddon matrix evaluation. Sports Med. 2015; 45(8): 1175-1190, doi: 10.1007/s40279-015-0334-7, indexed in Pubmed: 25946993.
43. Mahmood B, Duggal N. Lower extremity injuries in snowboarders. Am J Orthop (Belle Mead NJ). 2014; 43(11): 502-505, indexed in Pubmed: 25379746.

44. Stenroos A, Handolin L. Incidence of recreational alpine skiing and snowboarding injuries: six years experience in the largest ski resort in Finland. Scand J Surg. 2015; 104(2): 127-131, doi: 10.1177/1457496914532249, indexed in Pubmed: 24786173.

45. Radwin MI, Grissom CK. Technological advances in avalanche survival. Wilderness Environ Med. 2002; 13(2): 143-152, doi: 10.1580/1080-6032(2002)013[0143:taias]2.0.co;2, indexed in Pubmed: 12092969.

46. Radwin M, Grissom C, Scholand M, et al. Normal oxygenation and ventilation during snow burial by the exclusion of exhaled carbon dioxide. Wilderness \& Environmental Medicine. 2001; 12(4): $256-$ 262, doi: 10.1580/1080-6032(2001)012[0256:noavds]2.0.co;2.

47. Korzeniewski K. Health problems in high mountain conditions [in Polish]. Pol Merk Lek. 2008; 25(146): 161-165, indexed in Pubmed: 18942339.

48. Dietz TE, Hackett PH. High-Altitude Medicine. In: Keystone JS, Kozarsky PE, Connor BA, Northdurft HD, Mendelson M, Leder K. Travel Medicine. Fourth Edition. Elsevier Inc., USA 2019: 387-400.

49. Hartman-Ksycińska A, Kluz-Zawadzka J, Lewandowski B. High altitude illness. Przegl Epidemiol. 2016; 70(3): 490-499, indexed in Pubmed: 27888818

50. Jülg B, Elias J, Zahn A, et al. Bat-associated histoplasmosis can be transmitted at entrances of bat caves and not only inside the caves. J Travel Med. 2008; 15(2): 133-136, doi: 10.1111/j. 1708-8305.2008.00193.x, indexed in Pubmed: 18346250.

51. Norman FF, Martín-Dávila P, Fortún J, et al. Imported histoplasmosis: two distinct profiles in travelers and immigrants. J Travel Med. 2009; 16(4): 258-262, doi: 10.1111/j.1708-8305.2009.00311.x, indexed in Pubmed: 19674266.

52. Krebs JW, Noll HR, Rupprecht CE, et al. Rabies surveillance in the United States during 2001. J Am Vet Med Assoc. 2002; 221(12): 1690-1701, doi: 10.2460/javma.2002.221.1690, indexed in Pubmed: 12494966.

53. Messenger SL, Smith JS, Rupprecht CE. Emerging epidemiology of bat-associated cryptic cases of rabies in humans in the United States. Clin Infect Dis. 2002; 35(6): 738-747, doi: 10.1086/342387, indexed in Pubmed: 12203172.

54. Mortimer R. Leptospirosis in a Caver Returned from Sarawak, Malaysia. Wilderness \& Environmental Medicine. 2005; 16(3): 129-131, doi: 10.1580/1080-6032(2005)16[129:liacrf]2.0.co;2. 